\title{
К ВОПРОСУ О ПРИНЦИПАХ ПРОВЕДЕНИЯ АНТИКОРРУПЦИОННОЙ ЭКСПЕРТИЗЫ НОРМАТИВНЫХ ПРАВОВЫХ АКТОВ И ИХ ПРОЕКТОВ
}

\begin{abstract}
Аннотация: В статье рассматриваются основные принципы антикоррупционной экспертизы нормативных правовых актов, их сущность и возникающие при их применении проблемы. Анализируются сложности определения требований к образованию и компетентности лии, проводящих антикоррупционную экспертизу нормативных правовых актов, оценки нормативного правового акта во взаимосвязи с другими нормативными правовыми актами. Рассматривается требование обоснованности, объективности и проверяемости результатов антикоррупционной экспертизы. Поднимается вопрос обеспечения возможности сотрудничества независимых экспертов и органов государственной власти в ходе проведения антикоррупционной экспертизы. В рамках статьи исследуются проблемы, возникающие при применении принципов антикоррупционной экспертизы, и предлагаются способы их разрешения. При проведении исследования был использован метод текстуального анализа законодательных актов, диалектико-материалистический метод научного познания, методы социально-правового исследования, а именно сравнительно-правовой, формально-логический. Делается вывод о том, что именно принципы антикоррупционной экспертизы призваны регулировать проведение антикоррупционной экспертизы, устанавливать рамки и характер функкионирования разработчиков нормативных правовых актов и экспертов, в чем и состоит их особенная ценность. Полученные выводы и обобщения будут способствовать развитию антикоррупционной политики.

Ключевые слова: антикоррупционная экспертиза, нормативные правовые акты, принципы проведения, обязательность, обоснованность, объективность, проверяемость, независимые эксперты, сотрудничество, органы исполнительной власти.
\end{abstract}

$Э$ кспертиза на коррупциогенность, как правовой институт, обладает рядом основных принципов, которые мы и рассмотрим в настоящей статье. Федеральный закон «Об антикоррупционной экспертизе нормативных правовых актов и проектов нормативных правовых актов» $\left.{ }^{1}\right]$ выделил следующие принципы:

1) обязательность проведения антикоррупционной экспертизы проектов нормативных правовых актов.

Прежде чем приступить к непосредственной характеристике данного принципа, необходимо обратить внимание на одну деталь: обязанность проводить экспертизу на коррупциогенность не распространяется на действующие нормативные правовые акты. Следует согласиться с Н.П. Алешковой, которая объясняет это тем, что «с одной стороны, это согласуется с превентивной функцией экспертизы; с другой стороны, содержание анти-

Ст.2 Ф3 “Об антикоррупционной экспертизе нормативных правовых актов и проектов нормативных правовых актов” от 17 июля 2009 г. N 172-ФЗ. СЗ РФ. 2009. N 29 ст. 3609. коррупционной экспертизы (см. ст. 1 ФЗ № 172[ㄹ]) прямо указывает на объект проверки, включающий помимо проектов действующие нормативные правовые акты. Однако по смыслу ст. 3 (например, п. 3, 4 Ф3 № $172\left[{ }^{3}\right]$ ) антикоррупционная экспертиза действующих правовых актов должна проводиться при осуществлении мониторинга их применения. В свою очередь, мониторинг применения вступивших в законную силу правовых актов является обязанностью любого правотворческого органа и неотъемлемой частью правотворческой деятельности в целом. Кроме того, к мерам по профилактике коррупции отнесено рассмотрение в органах местного самоуправления, других органах,

\footnotetext{
См.: Федеральный закон от 17.07.2009 г. № 172-Ф3 «Об антикоррупционной экспертизе нормативных правовых актов и проектов нормативных правовых актов» // СЗ РФ. 2009. № 29 ст. 3609. ст.1.

См.: Федеральный закон от 17.07.2009 г. № 172-Ф3 «Об антикоррупционной экспертизе нормативных правовых актов и проектов нормативных правовых актов» // СЗ РФ. 2009. № 29 ст. 3609.
} 
организациях, наделенных федеральным законом публичными полномочиями, не реже одного раза в квартал вопросов правоприменительной практики по результатам вступивших в законную силу решений судов, арбитражных судов о признании недействительными ненормативных правовых актов, незаконными решений и действий (бездействия) указанных органов, организаций и их должностных лиц в целях выработки и принятия мер по предупреждению и устранению причин выявленных нарушений»[].

В общеправовом смысле, рассматриваемый нами принцип предполагает обязанность государственных органов проводить антикоррупционную экспертизу каждого проекта нормативного правового акта.

Некоторые исследователи более подробно описывают этот принцип. С точки зрения этих авторов, принцип подразумевает обязательность проведения данного вида экспертизы в процессе осуществления правотворческой деятельности и выполнения тех выводов, которые содержатся в заключении эксперта, группы (комиссии) экспертов или экспертного учреждения либо в актах прокурорского реагирования (требованиях) и/или судебных решениях $\left.{ }^{5}\right]$.

Впрочем, прежде чем говорить об обязательности выполнения выводов эксперта, необходимо отметить, что этому должна предшествовать обязанность разработчиков проектов нормативных правовых актов предоставить «возможность знакомиться с проектами нормативных правовых актов неограниченному кругу лиц, в том числе независимым экспертам, заключения которых должны в обязательном порядке рассматриваться разработчиками нормативных правовых актов» [']. В настоящее время такая возможность обеспечивается обязанностью государственных органов, ответственных за разработку проекта нормативного правового акта, размещать этот проект в сети Интернет.

\footnotetext{
4 Алешкова Н.П. Принципы проведения антикоррупционной экспертизы нормативных правовых актов и их проектов // Государственная власть и местное самоуправление. 2013, № 5 .

5 Агеев В.Н., Бикмухаметов А.Э., Матковский П.А., Кабанов С.В. Принципы организации производства антикоррупционной экспертизы нормативных правовых актов и их проектов в современной России // Следователь. 2010. №2. С. 6.

6 Воронина Ю.И. К вопросу о содержании принципов антикоррупционной экспертизы нормативных правовых актов и их проектов в Российской Федерации // Вестник Умуртского университета. 2013, вып.1.
}

2) оценка нормативного правового акта во взаимосвязи с другими нормативными правовыми актами.

Проблема заключается в том, что в основном, проверяется сам нормативный акт без учета его в системе других нормативных правовых актов и всех затрагиваемых правоотношений. Причиной этого является, как справедливо отмечено в научной литературе, то, что в этом случае «затруднительным становится даже процесс выявления всей совокупности этих актов, не говоря о проблемах с выявлением возможных вплетений коррупционных схем, которые отнюдь не всегда основаны на коррупциогенности правовых норм» [ [7]. Именно поэтому большое количество экспертов анализирует только отдельный правовой акт без учета связанных с ним актов, что значительно снижает эффективность антикоррупционной экспертизы. Кроме того, «для наиболее прицельного и оперативного выявления коррупционных технологий, которые основываются на использовании недостатков законодательных и иных нормативных правовых актов, требуется проведение мониторинга не только самих актов, но и практики их применения» $\left.{ }^{8}\right]$. А.В. Нестеров также поддерживает такую точку зрения, говоря о том, что «непригодность нормы можно выявить только на этапе правоприменительной практики» $\left.{ }^{9}\right]$.

Разделяя мнение исследователей, мы считаем, что оценка коррупциогенности должна проводиться не только во взаимосвязи с другими нормативными правовыми актами, но и взаимосвязанных нормативных правовых актов. Объективная антикоррупционная экспертиза нормативного правового акта невозможна без анализа иных нормативных правовых актов, составляющих с представленным на экспертизу правовым актом единый массив нормативных предписаний, ком-

\footnotetext{
Богатиков А.А., Грачев В.А., Пушкарев А.А. Почему в России не работает институт независимой антикоррупционной экспертизы // Экономическая преступность сегодня. 21.03.2011 // URL: http://econcrime.ru/expert/8/ (дата обращения 20.11.2013).

8 Астанин В.В. Обеспечение репрезентативности экспертизы на коррупциогенность проектов нормативных правовых актов. Антикоррупционная экспертиза нормативноправовых актов и их проектов / М-во образования и науки Рос. Федерации, Моск. гос. юрид. акад. им. О. Е. Кутафина; [сост. Е. Р. Россинская]. - М.: Проспект, 2010. С. 6.

9 Нестеров, А. В. О судебном антикоррупционном нормоконтроле /А. В. Нестеров // Право и безопасность. -2010. № 3. - C. 58.
} 
плексно и системно регулирующих общественные отношения, входящие в предмет правового регулирования.

Кроме того, следует обратить внимание на формулировку принципа: «это единственный из названных в статье пяти принципов, не содержащий указание на проекты нормативных правовых актов» $\left[{ }^{10}\right]$. Поддерживая точку зрения Д.Ю. Гончарова, мы считаем, что необходимо проводить оценку не только принятых нормативных правовых актов, но и проектов во взаимосвязи с другими нормативными правовыми актами. Очевидно, что такая оценка, проведенная еще на стадии подготовки нормативного правового акта, наиболее эффективна, поскольку нормативно правовой акт в этом случае будет изначально соответствующего качества и не потребует дополнительных и временных затрат на его корректировку в стадии правоприменения.

Таким образом, считаем необходимым проводить оценку нормативного правового акта и проекта нормативного правового акта:

во взаимосвязи с другими нормативными правовыми актами;

и взаимосвязанных нормативных правовых актов;

и практики его применения.

Такая расширенная характеристика принципа обязывает нас изменить его название. Наиболее подходящим вариантом, на наш взгляд, было бы: «системность подхода к оценке нормативного правового акта (проекта нормативного правового акта)».

А.А. Богатиков, В.А. Грачев и А.А. Пушкарев характеризуют такой комплексный подход к оценке коррупциогенности норм как сложный с точки зрения «выявления всего богатства регулируемых отношений, взаимосвязей и взаимного влияния социально-экономических явлений и участвующих в них лиц» и призывающий улучшать существующие и разрабатывать новые методы осуществления экспертиз на коррупциогенность» $\left[{ }^{11}\right]$.

Несмотря на трудоемкость метода скурпулезного изучения отдельного акта во взаимосвязи с

\footnotetext{
10 Гончаров, Д. Ю. Взаимосвязь нормативных правовых актов как принцип антикоррупционной экспертизы /Д. Ю. Гончаров. //Российская юстиция. -2010. - № 1.

11 Богатиков А.А., Грачев В.А., Пушкарев А.А. Почему в России не работает институт независимой антикоррупционной экспертизы // Экономическая преступность сегодня. 21.03.2011 // URL: http://econcrime.ru/expert/8/ (дата обращения 20.11.2013).
}

другими нормативными правовыми актами документов, а также правоприменительной практики, мы считаем, что этот метод отлично зарекомендовал себя и является наиболее эффективным при выявлении коррупциогенных факторов в нормативных правовых актах. Применение автоматизированных систем поиска нормативных правовых актов значительно облегчает выявление всей совокупности актов.

Кроме того, было бы логичным включить в список сопроводительных документов для проекта нормативного правового акта перечень взаимосвязанных актов для экспертов. Разработчику, как узкому специалисту в своей области, гораздо проще составить такой перечень, нежели эксперту.

3) обоснованность, объективность и проверяемость результатов антикоррупционной экспертизы нормативных правовых актов (проектов нормативных правовых актов).

Обоснованность результатов антикоррупционной экспертизы подразумевает, во-первых, то, что вывод, полученный экспертом при проведении экспертизы, сделан на основе тщательной оценки нормативного правового акта (или его проекта) на предмет соответствия его правовым, экономическим и политическим реалиям. Во-вторых, содержит обоснования такого вывода с опорой на теорию и правоприменительную практику. В-третьих, предусматривает прогноз последствий правоприменения нормативного правового акта, тем самым предупреждая злоупотребления государственными органами и их должностными лицами своего служебным положением.

Объективность результатов антикоррупционной экспертизы означает именно независимое проведение исследования. «Объективность, таким образом, обусловлена незаинтересованностью любого эксперта в исходе дела, его беспристрастностью, независимостью по службе или иным образом от лиц, принимающих решение по тому или иному вопросу» $\left[{ }^{12}\right]$.

Проверяемыми результаты антикоррупционной экспертизы являются тогда, когда существует возможность проверки истинности этих результатов, то есть, исследование проведено по четко описанным в официальной методике критериям, выводы логичны, имеют законное

\footnotetext{
12 Антикоррупционная экспертиза нормативных правовых актов и их проектов: проблемы теории и практики: монография / Е.Р. Россинская, Е. И. Галяшина. - М. : Норма : ИНФРА-М, 2014. С. 34.
} 
основание и «воспроизводимы при повторном исследовании» $\left[{ }^{13}\right]$. Однако, следует согласиться с Н.П. Алешковой, что данный принцип в настоящее время является скорее декларативным[14].

Однако, по верному замечанию А. Филатовой, «несмотря на соблюдение названных принципов, на практике даже проведенная экспертиза и официальный вариант заключения зачастую игнорируются, причем самим органом, его утвердившим, так как отсутствуют обязательность экспертного заключения и ответственность за неисполнение его положений» $\left.{ }^{15}\right]$. Как утверждают независимые эксперты, К.Е. Рыбак и Ю.С. Избачков, «поступающие в государственные органы заключения экспертизы часто просто не регистрируются... на официальных сайтах ведомств общественности для обсуждения предлагается один нормативноправовой акт, а в итоге издается другой, коренным образом отличающийся от обсуждаемого, хотя и имеющий то же самое название» $\left[{ }^{16}\right]$.

На сегодняшний день, проблема, отмеченная указанными правоведами, минимизирована - создан специальный сайт в сети «Интернет», на котором федеральные органы исполнительной власти обязаны публично размещать проекты нормативных правовых актов. Кроме того, вся информация по изменениям актов доводится до Минюста РФ $\left[{ }^{17}\right]$.

Добиться соблюдения принципа проверяемости, на наш взгляд, будет возможно, когда методиче-

13 Антикоррупционная экспертиза нормативных правовых актов и их проектов: проблемы теории и практики: монография / Е.Р. Россинская, Е. И. Галяшина. - М. : Норма : ИНФРА-М, 2014. С. 35.

14 Алешкова Н.П. Принципы проведения антикоррупционной экспертизы нормативных правовых актов и их проектов // Государственная власть и местное самоуправление. 2013, № 5.

15 Каменская Е.В., Рождествина А.А. Независимая антикоррупционная экспертиза. Научно-практическое пособие. - Система ГАРАНТ, 2010 г. - С. 89.

16 Избачков, Ю. С. О качестве антикоррупционных экспертиз / Избачков Ю. С., Рыбак К. Е. // Культура: управление, экономика, право. - 2011. - № 1. - С. 34.

17 П.5 Постановления Правительства РФ от 26.02.2010 № 96 (ред. от 27.03.2013) “Об антикоррупционной экспертизе нормативных правовых актов и проектов нормативных правовых актов" (вместе с “Правилами проведения антикоррупционной экспертизы нормативных правовых актов и проектов нормативных правовых актов”, “Методикой проведения антикоррупционной экспертизы нормативных правовых актов и проектов нормативных правовых актов") (с изм. и доп., вступающими в силу с 15.04.2013) // СПС «Консультант Плюс». ские рекомендации по проведению антикоррупционной экспертизы будут четко сформулированы, и позволят проверить результаты антикоррупционной экспертизы, провести «сравнительный анализ выводов, содержащихся в экспертном заключении, с некими стандартами ее [антикоррупционной экспертизы - отмечено Б.М.] проведения» $\left.{ }^{18}\right]$.

4) компетентность лиц, проводящих антикоррупционную экспертизу нормативных правовых актов (проектов нормативных правовых актов).

Компетентность экспертов является важной составляющей при проведении антикоррупционной экспертизы, поскольку именно от знаний и опыта этих лиц зависит результат проводимого ими исследования. В связи с этим, Селезнева О.В. высказывает идею введения спецкурса «Правовая экспертиза» в учреждениях высшего и среднего профессионального образования по всем юридическим и по большинству экономических специальностей[19]. Хабриева Т.Я. заостряет внимание на задаче организации обучения государственных служащих, независимых экспертов, а также иных лиц, проводящих антикоррупционную экспертизу. Автор отмечает, что «учебные программы, направленные на предотвращение коррупции, применяются во многих иностранных государствах. Программы по предотвращению коррупции, в основном в рамках курсов повышения квалификации руководящих кадров, существуют в Мексике, США, Великобритании, Франции, Италии, ФРГ и других государствах. В последние годы учебные курсы, направленные на предупреждение коррупции, создаются и международными организациями (ОOH, Всемирным банком, Интерполом). В целом в мире совершенно отчетливо прослеживается тенденция к созданию специализированных учебных программ по предупреждению коррупции в государственной службе $\left[{ }^{20}\right]$.

Совершенно очевидно, что для подготовки экспертного заключения высокого уровня требуется юрист, прошедший специальное обучение по

\footnotetext{
18 Алешкова Н.П. Принципы проведения антикоррупционной экспертизы нормативных правовых актов и их проектов // Государственная власть и местное самоуправление. 2013, № 5 .

19 Селезнева О.В. О некоторых проблемах организации правовой экспертизы // Право: Теория и Практика. 2003. № 8. С. 61-63.

20 Хабриева Т.Я. Формирование правовых основ антикоррупционной экспертизы нормативных правовых актов // Журнал российского права. 2009. № 10.
} 
правовой экспертизе (и имеющий соответствующее подтверждение прохождения обучения). Причем, чем выше коррупционные риски принимаемого нормативного правового акта и чем большее количество правоотношений он затрагивает, тем выше требования должны предъявляться к эксперту: ученые степени и звания, более продолжительный опыт работы, наличие научных трудов в соответствующей сфере регулирования исследуемого проекта нормативного правового документа. Разделяя мнение 0.А. Селезневой, «целесообразно предусмотреть процедуру конкурсного отбора экспертов. В качестве образца можно рассмотреть практику, сложившуюся при формировании состава судебных экспертов»[ $\left.{ }^{21}\right]$. Так, согласно ст. 86 АПК РФ и ст. 204 УПК РФ в заключении эксперта должны быть отражены, кроме прочего, сведения о государственном судебно-экспертном учреждении, об эксперте (фамилия, имя, отчество, образование, специальность, стаж работы, ученая степень и ученое звание, занимаемая должность), которым поручено проведение судебной экспертизы. Таким образом, стороны в судебном процессе имеют возможность ознакомиться с этими сведениями и апеллировать к уровню профессионализма и компетентности эксперта другой стороны, а судья соглашается с высказанным мнением или нет, в чем и выражается конкурсный отбор экспертов. Применительно к нашему исследованию, такой отбор должен осуществляться органами, непосредственно проводящими экспертизу на коррупциогенность нормативных правовых актов.

5) сотрудничество федеральных органов исполнительной власти, иных государственных органов и организаций, органов государственной власти субъектов Российской Федерации, органов местного самоуправления, а также их должностных лиц (далее сокращается так: органы, организации, их должностные лица) с институтами гражданского общества при проведении антикоррупционной экспертизы нормативных правовых актов (проектов нормативных правовых актов).

В литературе существуют разные точки зрения на содержание и смысл этого пункта. Каменская Е.В. и Рождествина А.А. рассматривают данный принцип как «обеспечение возможности независимым экспертам получать со стороны органов государственной власти необходимую информацию в ходе

21 Селезнева О.В. О некоторых проблемах организации правовой экспертизы // Право: Теория и Практика. 2003. № 8. С. 61-63. проведения антикоррупционной экспертизы»[22]. Гончаров Д.Ю. видит в этом принципе «возможность осуществления независимой антикоррупционной экспертизы гражданами и институтами гражданского общества за счет собственных средств и обязанность указания в заключении по результатам экспертизы на выявленные в нормативном правовом акте (проекте нормативного правового акта) коррупциогенные факторы» $\left[{ }^{23}\right]$.

Думается, что государственные органы должны не только принимать к сведению полученные от независимых экспертов заключения, но и реагировать на них: различным образом взаимодействовать с институтами гражданского общества, например, оказывать поддержку независимым экспертам в их деятельности, проводить общественное обсуждение наиболее важных законопроектов на Интернет-сайтах государственных органов, в СМИ, на научно-практических конференциях. Такая практика уже применяется в Уральском федеральном округе. Так, обеспечивается доступ граждан к информации о деятельности государственных и муниципальных служащих, налажена работа электронного почтового адреса. По мнению члена Общественной палаты Свердловской области Владимира Винницкого, «в регионе создан и действует новый механизм обратной связи между гражданским обществом и всей государственно-политической системой в регионе. То есть, законодательные, нормативные акты и решения органов власти принимаются с учётом экспертного мнения и позиции соответствующих институтов гражданского общества региона. При подготовке проектов законов Свердловской области принято решение: все законопроекты, затрагивающие права и свободы человека, основные направления социально-экономического развития области, до внесения в областной парламент должны проходить широкое общественное обсуждение. Это решение закреплено Указом Губернатора «Об общественном обсуждении проектов законов Свердловской области» $\left[{ }^{24}\right]$. В Тюменской области в государственном университете действует группа независимых экспертов, дающих

22 Каменская Е.В., Рождествина А.А. Независимая антикоррупционная экспертиза. Научно-практическое пособие. Система ГАРАНТ, 2010 г. - С. 87.

23 Гончаров Д.Ю. Взаимосвязь нормативных актов как принцип антикоррупционной экспертизы // Российская юстиция. 2010. №1.

24 Указ Губернатора Свердловской области от 09.03.2011 № 142-УГ «Об общественном обсуждении проектов законов Свердловской области» // Областная газета, № 72, 11.03.2011. 
оценку нормативным актам. В Ханты-Мансийском автономном округе молодежный парламент выявил более четырех тысяч ошибок в документах»[25].

В заключение хотелось бы отметить, что роль вышеперечисленных принципов сложно пере- оценить, именно они призваны регулировать проведение антикоррупционной экспертизы, устанавливать рамки и характер функционирования разработчиков нормативных правовых актов и экспертов.

\section{Библиография:}

1. Агеев В.Н., Бикмухаметов А.Э., Матковский П.А., Кабанов С.В. Принципы организации производства антикоррупционной экспертизы нормативных правовых актов и их проектов в современной России // Следователь. 2010. №2. C. 6.

2. Воронина Ю.И. К вопросу о содержании принципов антикоррупционной экспертизы нормативных правовых актов и их проектов в Российской Федерации // Вестник Умуртского университета. 2013, вып.1.

3. Алешкова Н.П. Принципы проведения антикоррупционной экспертизы нормативных правовых актов и их проектов // Государственная власть и местное самоуправление. 2013, N 5.

4. Астанин В.В. Обеспечение репрезентативности экспертизы на коррупциогенность проектов нормативных правовых актов. Антикоррупционная экспертиза нормативно-правовых актов и их проектов / М-во образования и науки Рос. Федерации, Моск. гос. юрид. акад. им. О. Е. Кутафина; [сост. Е. Р. Россинская].-М.: Проспект, 2010.

5. Богатиков А.А., Грачев В.А., Пушкарев А.А. Почему в России не работает институт независимой антикоррупционной экспертизы // Экономическая преступность сегодня. 21.03.2011 [Электронный ресурс]. - Режим доступа: http://econcrime.ru/expert/8/ (дата обращения 20.11.2013).

6. Гончаров Д.Ю. Взаимосвязь нормативных актов как принцип антикоррупционной экспертизы // Российская юстиция. 2010. №1.

7. Избачков, Ю. С. О качестве антикоррупционных экспертиз / Избачков Ю. С., Рыбак К. Е. // Культура: управление, экономика, право.-2011.-N 1.

8. Каменская Е.В., Рождествина А.А. Независимая антикоррупционная экспертиза. Научно-практическое пособие. Система ГАРАНТ, 2010 г.

9. Нестеров, А. В. О судебном антикоррупционном нормоконтроле /А. В. Нестеров // Право и безопасность--2010.-№ 3.

10. Официальный сайт Правительства Свердловской области. URL: http://www.midural.ru/news/100046/ document15086/ (дата обращения: 12.06.2013).

11. Россинская Е.Р., Галяшина Е. И.. Антикоррупционная экспертиза нормативных правовых актов и их проектов: проблемы теории и практики: монография. - М. : Норма : ИНФРА-М, 2014. С. 34.

12. Селезнева О.В. О некоторых проблемах организации правовой экспертизы // Право: Теория и Практика. $2003 . \mathrm{N} 8$

13. Хабриева Т.Я. Формирование правовых основ антикоррупционной экспертизы нормативных правовых актов // Журнал российского права. 2009. N 10.

14. ФЗ "Об антикоррупционной экспертизе нормативных правовых актов и проектов нормативных правовых актов" от 17 июля 2009 г. N 172-ФЗ. СЗ РФ. 2009. N 29.

15. Кабанов П.А. Юридико-лингвистическая неопределенность как предмет антикоррупционной экспертизы нормативных правовых актов и проектов нормативных правовых актов // NB: Административное право и практика администрирования. - 2014. - 3. - С. 61 - 71. DOI: 10.7256/2306-9945.2014.3.12055. URL: http://www.e-notabene. $\mathrm{ru} / \mathrm{al} /$ article_12055.html

16. Романова И.С. Компетентность лиц, проводящих антикоррупционную экспертизу нормативных правовых актов и их проектов. // Административное и муниципальное право. - 2014. - 1. - С. 65 - 69. DOI: 10.7256/19992807.2014.1.10160.

\section{References (transliterated):}

1. Ageev V.N., Bikmukhametov A.E., Matkovskii P.A., Kabanov S.V. Printsipy organizatsii proizvodstva antikorruptsionnoi ekspertizy normativnykh pravovykh aktov i ikh proektov v sovremennoi Rossii // Sledovatel'. 2010. №2. S. 6.

2. Voronina Yu.I. K voprosu o soderzhanii printsipov antikorruptsionnoi ekspertizy normativnykh pravovykh aktov i ikh proektov v Rossiiskoi Federatsii // Vestnik Umurtskogo universiteta. 2013, vyp.1.

3. Aleshkova N.P. Printsipy provedeniya antikorruptsionnoi ekspertizy normativnykh pravovykh aktov i ikh proektov // Gosudarstvennaya vlast' i mestnoe samoupravlenie. 2013, N 5.

4. Astanin V.V. Obespechenie reprezentativnosti ekspertizy na korruptsiogennost' proektov normativnykh pravovykh aktov. Antikorruptsionnaya ekspertiza normativno-pravovykh aktov i ikh proektov / M-vo obrazovaniya i nauki Ros. Federatsii, Mosk. gos. yurid. akad. im. O. E. Kutafina; [sost. E. R. Rossinskaya].-M.: Prospekt, 2010.

25 Официальный сайт Правительства Свердловской области http://www.midural.ru/news/100046/document15086/ 
5. Bogatikov A.A., Grachev V.A., Pushkarev A.A. Pochemu v Rossii ne rabotaet institut nezavisimoi antikorruptsionnoi ekspertizy // Ekonomicheskaya prestupnost' segodnya. 21.03.2011 [Elektronnyi resurs]. - Rezhim dostupa: http://econcrime.ru/expert/8/ (data obrashcheniya 20.11.2013).

6. Goncharov D.Yu. Vzaimosvyaz' normativnykh aktov kak printsip antikorruptsionnoi ekspertizy // Rossiiskaya yustitsiya. 2010. №1.

7. Izbachkov, Yu. S. O kachestve antikorruptsionnykh ekspertiz / Izbachkov Yu. S., Rybak K. E. // Kul'tura: upravlenie, ekonomika, pravo.-2011.-N 1.

8. Kamenskaya E.V., Rozhdestvina A.A. Nezavisimaya antikorruptsionnaya ekspertiza. Nauchno-prakticheskoe posobie. Sistema GARANT, $2010 \mathrm{~g}$.

9. Nesterov, A. V. O sudebnom antikorruptsionnom normokontrole /A. V. Nesterov // Pravo i bezopasnost'.-2010.-№ 3.

10. Ofitsial'nyi sait Pravitel'stva Sverdlovskoi oblasti. URL: http://www.midural.ru/news/100046/document15086/ (data obrashcheniya: 12.06.2013).

11. Rossinskaya E.R., Galyashina E. I.. Antikorruptsionnaya ekspertiza normativnykh pravovykh aktov i ikh proektov: problemy teorii i praktiki: monografiya. - M. : Norma : INFRA-M, 2014. S. 34.

12. Selezneva O.V. O nekotorykh problemakh organizatsii pravovoi ekspertizy // Pravo: Teoriya i Praktika. $2003 . \mathrm{N} 8$

13. Khabrieva T.Ya. Formirovanie pravovykh osnov antikorruptsionnoi ekspertizy normativnykh pravovykh aktov // Zhurnal rossiiskogo prava. 2009. N 10.

14. FZ "Ob antikorruptsionnoi ekspertize normativnykh pravovykh aktov i proektov normativnykh pravovykh aktov" ot 17 iyulya 2009 g. N 172-FZ. SZ RF. 2009. N 29.

15. Kabanov P.A. Yuridiko-lingvisticheskaya neopredelennost' kak predmet antikorruptsionnoi ekspertizy normativnykh pravovykh aktov i proektov normativnykh pravovykh aktov // NB: Administrativnoe pravo i praktika administrirovaniya. - 2014. - 3. - C. 61 - 71. DOI: 10.7256/2306-9945.2014.3.12055. URL: http://www.e-notabene.ru/al/article_12055.html

16. Romanova I.S. Kompetentnost' lits, provodyashchikh antikorruptsionnuyu ekspertizu normativnykh pravovykh aktov i ikh proektov. // Administrativnoe i munitsipal'noe pravo. - 2014. - 1. - C. 65 - 69. DOI: 10.7256/1999-2807.2014.1.10160. 